\title{
Multiple Sclerosis Clinic in Iraq, an Endeavourforan Unraveling Database
}

\author{
Haider Ali Mohammed ${ }^{1}$, Mohammed Majeed kamil' ${ }^{2}$, Hassan Naji Aboud ${ }^{1}$, Bahaa Hassan ${ }^{3}$ \\ ${ }^{1}$ Neurology Department, Neurosurgery Teaching Hospital, Baghdad, Iraq \\ ${ }^{2}$ Neurology Department, Baquba Teaching Hospital, Dyiala, Iraq \\ ${ }^{3}$ Neurology Department, Neurosciences Teaching Hospital, Baghdad, Iraq
}

Email address:

theneurologistbahaa@gmail.com (B. Hassan)

\section{To cite this article:}

Haider Ali Mohammed, Mohammed Majeed kamil, Hassan Naji Aboud, Bahaa Hassan. Multiple Sclerosis Clinic in Iraq, an Endeavourforan Unraveling Database. American Journal of Clinical and Experimental Medicine. Vol. 6, No. 3, 2018, pp. 69-82.

doi: 10.11648/j.ajcem.20180603.12

Received: February 28, 2018; Accepted: March 28, 2018; Published: May 29, 2018

\begin{abstract}
Multiple sclerosis (MS) is the most common disabling neurologic condition of young adults after trauma. The establishing of an unraveling database carries a potentially important role in clarifying the nature of the disease in Iraq. This study had been designed to find the frequency distribution of MS patients according to different demographic variables like the age at onset, age at diagnosis, gender and place of birth and residence, etc, to estimate the frequency of different neurological symptoms and signs in patients with MS, to estimate the frequency of different clinical types of MS in Iraqi patients and assessing the differences between different clinical types of MS in regard to gender, age at onset, age at diagnosis, the diagnostic delay, disease duration and the EDSS, accordingly. This retrospective study was carried out at the Multiple Sclerosis Clinic, Medical City in Baghdad/lraq. The medical files of 900 MS patients were thoroughly revised; they included all patients who had attended the MS Clinic from the day of establishment of the clinic at 2001 to the end of February 2006. Six hundreds seventy six (676) patients were considered as MS patients fulfilling the Poser's criteria and continued visiting the clinic for follow up and treatment. Patient's distribution according to the clinical type of their MS was RRMS $=67.3 \%$, PPMS $=19.1 \%$, $\mathrm{SPMS}=13.6 \%$, main age distribution of this sample was between $30-39$ years $(39.3 \%)$., Females were $64.9 \%$, males were $35.1 \%$.,Age of onset was mainly between 20-29 years of age regardless of the gender or type of MS, Diagnostic delay was mainly between 1-3 years, Distribution according to place of birth was seen mainly in 3 geographical clusters in Iraq, Motor symptoms were the commonest experienced by the patients (95.7\%). This study had shown that during the last 2 decades, MS was increasingly encountered in Iraq, particularly during the last 5 years after the establishment of MS clinic in Baghdad, MS cases in Iraq distributed in a three-main-clusters pattern rather than North-South gradient, primary progressive MS showed a more even gender distribution and older age at onset with the shortest diagnostic delay.
\end{abstract}

Keywords: Multiple Sclerosis, Iraqi Patients, Distribution

\section{Introduction}

Multiple sclerosis is the most common autoimmune inflammatory demyelinating disease of the central nervous system, and the most common disabling neurologic condition of young adults after trauma [1]. Since Charcot described the disease in 1868, a complete medical understanding of the disease has proved elusive. Theories and therapies litter the history of multiple sclerosis. It is a true historical maze from Robert Carswell's lithographic illustrations of post-mortem tissue "lesion (s) of the spinal cord accompanied with atrophy" of 1838 , to MRI now used to visualize lesions noninvasively in the living; from Charcot's triad of intention tremor, nystagmus, and scanning speech, to $20^{\text {th }}$ century diagnostic criteria; from a therapeutic approach, championed by Galen, of balancing the four humors to licensing of interferon beta in 1993 [2]. Oenly one aim was shared by all of these efforts, that was reaching the point of well understanding about the nature of this disabling illness.

Geography and MS: from the epidemiological point of view, the potentially important role played by the geographic 
factors, inducing this wide variability in the incidence and prevalence of multiple sclerosis in different geographic areas of the world had stimulated many research workers. Epidemiologic studies indicate that multiple sclerosis is much more common in persons of western European lineage who live in temperate zones [3]. Some authors reported that despite the wealth of epidemiological data deriving from systematic studies of multiple sclerosis that had been carried out for over 70 years, any attempt at redefining the pattern of multiple sclerosis' geographic distribution is still a difficult task [4]. In fact, comparing prevalence studies of different areas and at different times implies a number of problems, The variability of the surveyed populations in term of size, age structure, ethnic origin and composition [5]., The difference when determining the numerator, i.e. the recognition of benign and very early cases [6]., The extent to which complete case ascertainment is achieved based on geographic and time variables, access to medical care, local medical expertise, number of neurologists, availability of and accessibility of new diagnostic procedures, degree of public awareness about multiple sclerosis, and on the investigators' zeal and resources [6, 7]. The use of different diagnostic criteria and the inter-observer variability when applying them [5].

As mentioned above, differences in the risk of multiple sclerosis by region have been reported [8] The disease tends to be rare in tropical areas but common in temperate areas, although there are some exceptions [8, 9] Kurtzke has collated existing surveys and defined bands of multiple sclerosis prevalence [10].

Interestingly, no population at high risk for multiple sclerosis exists between latitudes $40^{\circ} \mathrm{N}$ and $40^{\circ} \mathrm{S}$. Genetic, dietary, and climatic factors can not account forthese differences [2] Iraq is a Country located in the Middle East, has an area of $438,317 \mathrm{sq} \mathrm{km}$ at latitudes $37^{\circ} .25^{\prime}-29^{\circ} 5^{\prime}[11]$. Therefore, Iraq as well as Middle East, geographically speaking, is considered as a low risk zone. However, the pattern of distribution of multiple sclerosis in this area of the world emphasizes the importance of genetic-historical factor in deriving the distribution of multiple sclerosis [4]. It had been reported that variations in prevalence are apparent over very small geographic distances [12, 13], partly reflecting geographic variations in ethnicity. This variability is not confined to low risk areas only; but even in areas where disease is common, some groups at lower risk, including the Samis, Turkmen, North and South Amerindians, Canadian Hutterites, African Americans, Eskimos and New Zealand Maoris [9, 14]. Studies of US army veterans identified a north-south gradient of decreasing risk and reflects the distribution of Scandinavian ancestry throughout the USA [15]. In the Middle East, this phenomenon is obvious on reviewing the results of an epidemiological study done at Kuwait 1988. This study showed that with a population of nearly two millions of whom about $75 \%$ were Arabs, the overall multiple sclerosis prevalence rate was 10 per 100000 . However, the prevalence rate observed among Palestinians living in Kuwait was 24 per 100 000. This difference can not be explained by environmental factors alone, since about $60 \%$ of the Palestinians in Kuwait were born there and the majority of the remaining $40 \%$ had migrated to Kuwait more than 20 years prior to prevalence day. An association with HLA-DR2 and HLA-DQWI, similar to that reported in Caucasians, observed in Palestinians multiple sclerosis patients but not in Kuwaitis, might explain a difference in the genetic control over the susceptibility to the disease [4]. Hopes have long been pinned on the identification of an interaction between multiple sclerosis susceptibility gene (s) and a mysterious environmental agent in the pathogenesis of this unsolved disease. Much is known about the genetics of MS, but little is known about the gene (s) [16].

Clinical Notes on MS: MS is characteristically variable in its manifestations and disease course, both between patients and within individual patients over time. Motor manifestations include weakness, spasticity, and ataxia. Weakness in MS is usually due to involvement of central motor pathways and is accompanied by hyperreflexia, spasticity, and abnormal cutaneous reflexes (e.g. a Babinski sign). MS can produce loss of sensation in any anatomic distribution and with any combination of loss of pain, temperature, light touch, vibratory sense, or position sense. Positive sensory phenomena are common, sensory symptoms were reported as the first symptom in $43 \%$ of patients [17].

Almost any pattern of visual loss has been reported in MS, depending on the site of involvement of the afferent visual system. Most typically, optic neuritis presents with unilateral eye pain, overall risk for the development of MS after 10 years was 38\% [18]. Abnormalities of eye movements, with diplopia as a common symptom, involvement of ocular cranial nerve nuclei, their fasciculi, or higher centers or their connections can produce virtually any eye movement abnormality. Lesions involving other cranial nerves or brain stem structures can produce loss of taste, facial weakness, loss of hearing, tinnitus/or vertigo, dysarthria and swallowing dysfunction. Cognitive dysfunction is a common, but frequently overlooked, manifestation of MS. The prevalence of cognitive problems has been estimated as high as $50 \%$ to $75 \%$ [19]. Detruser hyperactivity, urinary urgency, frequency and nocturia; detruser-sphincter dyssynergia, hesitancy, increased postvoid residual or urinary retention are all signs and symptoms of bladder dysfunction, occurring in up to $90 \%$ of patients with MS [20]. Often patients complain of constipation, which can be aggravated by fluid restriction or anticholinergic medications used to treat urinary symptoms. Some patients have bowel urgency and incontinence, erectile dysfunction in combination with bladder or bowel disturbances.

Fatigue is one of the most important sources of disability in MS in $60-90 \%$ of patients with MS [21]. Paroxysmal symptoms in MS occur in variable frequencies, including trigeminal neuralgia, tonic seizures, paroxysmal dysarthria \&/or aphasia, hemifacial spasm, abrupt loss of muscle tone and Lhermitte's sign [22].

Whether MS is a single disease with several subtypes or a combination of different diseases with similar clinical 
features complicates the issue of the clinical course of the disease [23].

\section{Aims of the Study}

This study had been designed to:

Make the starting point to build an unraveling database that includes all of the potentially important information about MS patients in Iraq.

Find the frequency distribution of MS patients according to different demographic variables like the age at onset, age at diagnosis, gender and place of birth and residence, etc. Estimate the frequency of different neurological symptoms and signs in patients with MS. Estimate the frequency of different clinical types of MS in Iraqi patients.

Assess the differences between different clinical types of MS in regard to gender, age at onset, age at diagnosis, the diagnostic delay, disease duration and the EDSS, accordingly.

\section{Patients and Methods}

This retrospective study was carried out at the Multiple Sclerosis Clinic, Medical City in Baghdad/Iraq, which is the only specialized clinic for treating MS patients in the country. Patients are referred from all over Iraq to this clinic in order to be enrolled in the program of treatment and follow-up services for this disease. The medical files of $900 \mathrm{MS}$ patients were thoroughly revised; they included all patients who had attended the MS Clinic from the day of establishment of the clinic at 2001 to the end of February 2006. Six hundreds seventy six (676) patients were considered as MS patients fulfilled the Poser's criteria [63] and continued visiting the clinic for follow up and treatment. Two hundreds twenty four patients had been excluded from the study either because they did not fulfill the Poser's criteria or because they did not continue visiting the clinic.

\section{Results}

The mean age of the 676 patients, whose files had been evaluated in this retrospective study, was $37.9 \pm 9.1$ year old. 388 out of them were younger than 40 year-old $(57.3 \%$ of the sample) and 13 patients (1.9\% of the sample) were younger than 20 year-old. Table-I show age distribution of the sample. This study's sample composed from 439 female $(64.9 \%$ of the sample) and 237 male patients (35.1\% of the sample) with female to male ratio (F: $\mathrm{M}$ ratio) of about 1.85:1. Table2 show the frequency distribution of the sample according to gender.

The mean age at onset of multiple sclerosis had been estimated to be $29.17 \pm 8.8$ year-old. This study showed that $5 \%$ of the sample (34 patients) had started to complain from their symptoms since being younger than 20 year-old, while the onset of the complaints of $2.5 \%$ of the sample (17 patients) was at the age of 50 years or older. Table- 3 show patients distribution according to their age at onset of symptoms suggestive of multiple sclerosis.
The mean age at diagnosis of multiple sclerosis was $32.6 \pm$ 8.9 year-old (range: 9-58year-old). Multiple sclerosis had been diagnosed before the age of 20 in 31 patients $(4.6 \%$ of the sample) and at the age of 50 years or older in 23 patients (3.4\% of the sample). Table-4 show patients distribution according to their age at time of diagnosis.

The time of delay between the onset of the symptoms and the diagnosis of multiple sclerosis was in an average of about $3.38 \pm 3.8$ years. The diagnosis of multiple sclerosis had been established within 1 year from the onset of multiple sclerosis related symptoms in 140 patients (20.7\% of the sample). Furthermore, the diagnostic delay was less than 4 years in 457 patients (67.6\% of the sample). Table-5 shows patients' distribution according to the delay in their diagnosis of multiple sclerosis.

The onset of multiple sclerosis in the patients who had been enrolled in this study, was between 1980 to 2005 . Only 10 patients $(1.5 \%$ of the sample) had an onset of multiple sclerosis before the year of 1985, while the onset in 314 patients $(46.4 \%$ of the sample) was at the year of 2000 or after. In regard to the year of diagnosis of multiple sclerosis, no one had been diagnosed before the year of 1985, while the diagnosis of multiple sclerosis had been achieved at the year of 2000 or after in 518 patients (76.6\% of the sample), it should be emphasized that the figures represent the patients in the MS Clinic, and that they do not mean that there was no MS patients in the country before the mentioned years. Table- 6 shows patients' distribution according to the year of onset and year of diagnosis of multiple sclerosis. The duration of having multiple sclerosis ranged between to 26 years $(8.6 \pm 5.06$ years $)$. Table- 7 shows patients' distribution according to the duration of their multiple sclerosis.

Table- 8 and figure- 1 show patients' distribution according to their place of birth.

Table-9 and figure-2 show patients' distribution according to their residence.

Five hundred fifty eight ( $82.5 \%$ of the sample), 96 (14.2\% of the sample) and 16 patients (2.4\% of the sample) were Arabs, Kurds or Turkmen respectively. Table-10 shows patients' distribution according to their ethnic origin.

Muslims comprised $97 \%$ of the sample (656 patients), Christians were 12 patients $(1.8 \%$ of the sample) and Mandaeans were 7 patients (1.04\% of the sample). Table 11 shows patients' distribution according to their religion.

Positive family history of multiple sclerosis among $1^{\text {st }}$ and $2^{\text {nd }}$ degree relatives had been detected in 45 patients $(6.7 \%$ of the sample). Table-12 show patients distribution according to their family history of multiple sclerosis.

Symptoms of motor, sensory, urinary and cerebellar abnormalities had been noticed in 647 (95.7\%), 441 (65.2\%), $400(59.2 \%)$ and 345 patients $(51.03 \%)$, respectively. Table13 shows patients' distribution according to their symptoms of multiple sclerosis.

Signs of pyramidal tract, optic nerve, and cerebellar involvements had been observed in 517 (76.5\%), 350 $(51.8 \%)$, and 344 patients $(50.9 \%)$, respectively. Table-14 show patients distribution according to their observed 
physical signs.

Regarding the clinical course of multiple sclerosis, it was relapsing remitting in 455 patients $(67.3 \%$ of the sample), primary progressive in 129 patients (19.1\% of the sample) and secondary progressive in 92 patients $(13.6 \%$ of the sample). Table-15 show patients distribution according to the clinical type of their multiple sclerosis.

Female to male ratio among patients with primary progressive multiple sclerosis was 1.01:1, while it was $2.3: 1$ among patients with relapsing remitting type. The mean age of onset observed in patients with PPMS was $39.6 \pm 12.2$ years, while it was $26.3 \pm 7.9$ years in patients with SPMS. Similarly, the mean age at diagnosis was $44.3 \pm 9.6$ years and $27.2 \pm 10.2$ years in patients with PPMS and SPMS, respectively. The mean time of delay between the onset and the diagnosis of multiple sclerosis was $1.3 \pm 1.9$ years and $3.5 \pm 3.7$ years in patients with PPMS and RRMS, respectively. Table-16 and show patients distribution according to the clinical type of multiple sclerosis and different demographic features.

The Kurtzke Expanded Disability Status Score (EDSS) of the patients included in this study ranged between 1-9 (3.9 \pm 1.8). This study had shown that the mean of the EDSS of patients having RRMS was $3.5 \pm 1.69$ with a range between $1-8$, while its mean among patients with SPMS was $6.2 \pm$ 1.01 , with no one of them had an EDSS of less than 4. Table17 and show patients distribution according to clinical type of multiple sclerosis and their EDSS.

At the time of diagnosis, all of patients with PPMS and SPMS and $97.8 \%$ of those with RRMS (445 patients had been treated with methyl prednisolone. At the time of this study, 121 patients 409 patients with RRMS (89.9\%), 29 patients with SPMS (31.5\%) and 8 patients with PPMS
$(6.2 \%)$ were treated with Rebif ${ }^{\circledR}$. Table-18 show patients distribution according to the clinical type of multiple sclerosis they had, and their treatment at diagnosis and at the time of the study.

The mean of EDSS among male patients was $3.98 \pm 2.02$ with a range between $1-9$, while it was $3.4 \pm 1.83$ with a range of 1-7.5 among female patients. In addition, $72.2 \%$ of female patients (317 patients) and $57.4 \%$ of the male patients (136 patients) had EDSS of 5 or less. Table-19 shows patients' distribution according to their gender and EDSS.

This study indicated that $72 \%$ of those who had MS for less than 5 years (108 patients) had an EDSS of 0-3.5, and only $1.3 \%$ of them ( 2 patients) had an EDSS of 7 or more. Table-20 show patients distribution according to their EDSS and disease duration.

Table 1. Patients' distribution according to their current age.

\begin{tabular}{lll}
\hline Current age (year-old) & No. & \% \\
\hline$<20$ & 13 & $1.9 \%$ \\
$20-29$ & 109 & $16.1 \%$ \\
$30-39$ & 266 & $39.3 \%$ \\
$40-49$ & 214 & $31.7 \%$ \\
$50-59$ & 64 & $9.5 \%$ \\
60 & 10 & $1.5 \%$ \\
Total & 676 & $100 \%$ \\
Range & $13-62$ & \\
Mean \pm SD & $37.9 \pm 9.1$ & \\
\hline
\end{tabular}

Table 2. Patients' distribution according to their gender.

\begin{tabular}{lll}
\hline Gender & No. & \% \\
\hline Female & 439 & $64.9 \%$ \\
Male & 237 & $35.1 \%$ \\
F:M ratio & $1.85: 1$ & \\
\hline
\end{tabular}

Table 3. Patients' distribution according to their age at onset with MS.

\begin{tabular}{|c|c|c|c|c|c|c|c|}
\hline \multirow{2}{*}{ Age at onset (year-old) } & \multicolumn{2}{|c|}{ Female } & \multicolumn{2}{|c|}{ Male } & \multirow{2}{*}{ F:M } & \multicolumn{2}{|c|}{ Regardless gender } \\
\hline & No. & $\%$ & No. & $\%$ & & No. & $\%$ \\
\hline$<20$ & 21 & $4.8 \%$ & 13 & $5.5 \%$ & $1.6: 1$ & 38 & $5 \%$ \\
\hline $20-29$ & 199 & $45.3 \%$ & 103 & $43.5 \%$ & $1.9: 1$ & 302 & $44.7 \%$ \\
\hline $30-39$ & 156 & $35.5 \%$ & 97 & $40.9 \%$ & $1.6: 1$ & 253 & $37.4 \%$ \\
\hline $40-49$ & 54 & $12.3 \%$ & 16 & $6.8 \%$ & $3.4: 1$ & 70 & $10.4 \%$ \\
\hline $50-59$ & 9 & $2.1 \%$ & 8 & $3.40 \%$ & $1.1: 1$ & 17 & $2.5 \%$ \\
\hline Total & 439 & $100 \%$ & 237 & $100 \%$ & $1.85: 1$ & 676 & $100 \%$ \\
\hline Range & \multicolumn{7}{|l|}{$7-56$} \\
\hline Mean $\pm \mathrm{SD}$ & \multicolumn{7}{|c|}{$29.17 \pm 8.8$} \\
\hline
\end{tabular}

Table 4. Patients' distribution according to theirage at time of diagnosis of MS.

\begin{tabular}{lll}
\hline Age at diagnosis (year-old) & No. & $\%$ \\
\hline$<20$ & 31 & $4.6 \%$ \\
$20-29$ & 219 & $32.4 \%$ \\
$30-39$ & 261 & $38.6 \%$ \\
$40-49$ & 142 & $21 \%$ \\
$50-59$ & 23 & $3.4 \%$ \\
Total & 676 & $100 \%$ \\
Range & $9-58$ & \\
Mean \pm SD & $32.6 \pm 8.9$ & \\
\hline
\end{tabular}


Table 5. Patients' distribution according to thediagnostic delay observed between thetime of onset and the diagnosis of MS.

\begin{tabular}{lll}
\hline Delay in diagnosis (year) & No. & \% \\
\hline$<1$ year & 140 & $20.7 \%$ \\
$1-3$ & 317 & $46.9 \%$ \\
$4-6$ & 88 & $13 \%$ \\
$7-9$ & 62 & $9.2 \%$ \\
10 & 69 & $10.2 \%$ \\
Total & 676 & $100 \%$ \\
Range & $0-20$ & \\
Mean \pm SD & $3.38 \pm 3.8$ & \\
\hline
\end{tabular}

Table 6. Patients' distribution according to the time of onset and diagnosis of MS.

\begin{tabular}{|c|c|c|c|c|}
\hline \multirow{2}{*}{ Year } & \multicolumn{2}{|c|}{ Onset of MS } & \multicolumn{2}{|c|}{ Diagnosis of MS } \\
\hline & No. & $\%$ & No. & $\%$ \\
\hline 1980-1984 & 10 & $1.5 \%$ & 0 & $0 \%$ \\
\hline 1985-1989 & 47 & $6.9 \%$ & 15 & $2.2 \%$ \\
\hline 1990-1994 & 135 & $19.9 \%$ & 58 & $8.6 \%$ \\
\hline 1995-1999 & 171 & $25.3 \%$ & 85 & $12.6 \%$ \\
\hline 2000 & 314 & $46.4 \%$ & 518 & $76.6 \%$ \\
\hline Total & 676 & $100 \%$ & 676 & $100 \%$ \\
\hline Range & 1980-2005 & & 1986-2005 & \\
\hline
\end{tabular}

Table 7. Patients' distribution according to the duration oftheir disease.

\begin{tabular}{|c|c|c|}
\hline Duration (year) & No. & $\%$ \\
\hline & 4 & $0.6 \%$ \\
\hline $2-4.9$ & 146 & $21.6 \%$ \\
\hline $5-9.9$ & 282 & $41.7 \%$ \\
\hline $10-14.9$ & 143 & $21.2 \%$ \\
\hline $15-19.9$ & 78 & $11.5 \%$ \\
\hline $20-24.9$ & 19 & $2.8 \%$ \\
\hline 25 & 4 & $0.6 \%$ \\
\hline Range & $1-26$ & \\
\hline Mean \pm SD & $8.6 \pm 5.06$ & \\
\hline
\end{tabular}

Table 8. Patients' distribution according to their place of birth.

\begin{tabular}{|c|c|c|c|c|c|}
\hline Place of birth & No. & $\%$ & Place of birth & No. & $\%$ \\
\hline Algeria & 1 & 0.15 & Karbala & 16 & $2.4 \%$ \\
\hline Anbar & 20 & $2.96 \%$ & Karkuk & 16 & $2.4 \%$ \\
\hline Babil & 19 & $2.8 \%$ & Wasit & 22 & $3.3 \%$ \\
\hline Baghdad & 320 & $47.3 \%$ & Missan & 13 & $1.9 \%$ \\
\hline Basra & 25 & $3.7 \%$ & Naynawa & 52 & $7.7 \%$ \\
\hline Qadisiyah & 19 & $2.8 \%$ & Muthana & 6 & $0.9 \%$ \\
\hline Diyala & 30 & $4.4 \%$ & Najaf & 16 & $2.4 \%$ \\
\hline Erbil & 18 & $2.7 \%$ & Suleimaniyah & 22 & $3.3 \%$ \\
\hline Finland & 1 & $0.15 \%$ & Salahuddin & 37 & $5.5 \%$ \\
\hline Iran & 5 & $0.7 \%$ & & & \\
\hline
\end{tabular}

Table 9. Patients' distribution according to their residence at time of registration inthe clinic.

\begin{tabular}{|c|c|c|c|c|c|}
\hline Residence & No. & $\%$ & Residence & No. & $\%$ \\
\hline Anbar & 19 & $2.8 \%$ & Karkuk & 16 & $2.4 \%$ \\
\hline Babil & 22 & $3.3 \%$ & Wasit & 21 & $3.1 \%$ \\
\hline Baghdad & 323 & $47.8 \%$ & Missan & 10 & $1.5 \%$ \\
\hline Basra & 19 & $2.8 \%$ & Naynawa & 53 & $7.8 \%$ \\
\hline Qadisiyah & 25 & $3.7 \%$ & Muthana & 6 & $0.9 \%$ \\
\hline Diyala & 47 & $6.9 \%$ & Najaf & 16 & $2.4 \%$ \\
\hline Dohuk & 8 & $1.2 \%$ & Dhiqar & 6 & $0.9 \%$ \\
\hline Erbil & 11 & $1.6 \%$ & Suleimaniyah & 22 & $3.3 \%$ \\
\hline Jordan & 1 & $0.15 \%$ & Salahuddin & 35 & $5.2 \%$ \\
\hline Karbala & 16 & $2.4 \%$ & & & \\
\hline
\end{tabular}




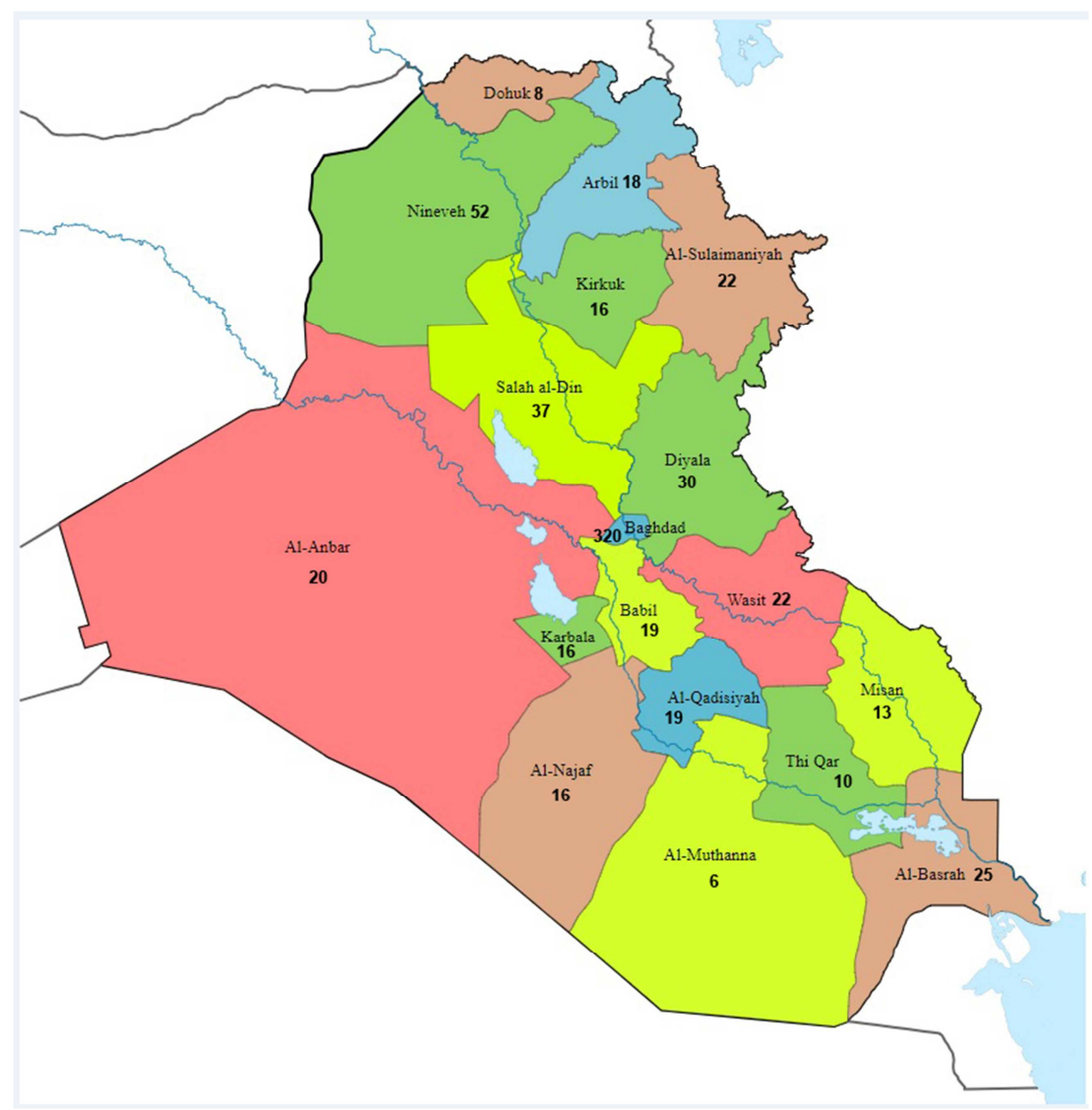

Figure 1. Patients distribution according to their place of birth in different Iraqi Governorates.

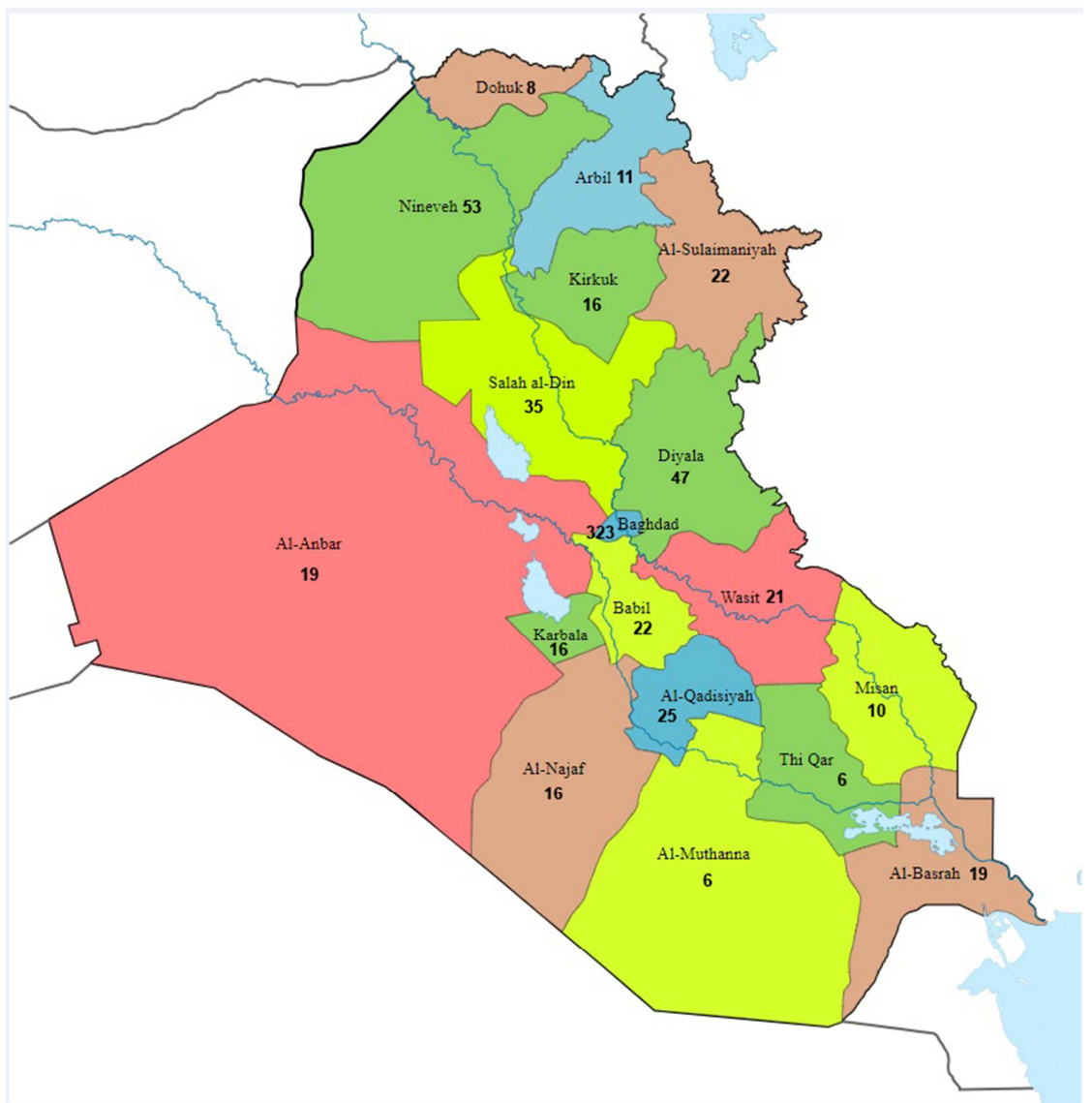

Figure 2. Patients distribution according to their site of residence in different Iraqi Governorates. 
Table 10. Patients' distribution according to their ethnic origin.

\begin{tabular}{lll}
\hline Ethnicity & No. & \% \\
\hline Indians & 1 & $0.15 \%$ \\
Iranians & 5 & $0.7 \%$ \\
Kurds & 96 & $14.2 \%$ \\
Turkmen & 16 & $2.4 \%$ \\
Arabs & 558 & $82.5 \%$ \\
Total & 676 & $100 \%$ \\
\hline
\end{tabular}

Table 11. Patients' distribution according to theirreligion.

\begin{tabular}{lll}
\hline Religion & No. & \% \\
\hline Christian & 12 & $1.8 \%$ \\
Yazidi & 1 & $0.15 \%$ \\
Mandaean & 7 & $1.04 \%$ \\
Muslim & 656 & $97 \%$ \\
Total & 676 & $100 \%$ \\
\hline
\end{tabular}

Table 12. Patients' distribution according to their familyhistoryof MS.

\begin{tabular}{lll}
\hline Family history & No. & $\%$ \\
\hline Positive family history & 45 & $6.7 \%$ \\
Negative family history & 631 & $93.3 \%$ \\
Total & 676 & $100 \%$ \\
\hline
\end{tabular}

Table 13. Patients' distribution according to theirsymptoms.

\begin{tabular}{|c|c|c|}
\hline Symptoms of MS & No. & $\%$ \\
\hline Motor symptoms & 647 & $95.7 \%$ \\
\hline Sensory symptoms & 441 & $65.2 \%$ \\
\hline Cerebellar symptoms & 345 & $51.03 \%$ \\
\hline Brainstem symptoms & 338 & $50 \%$ \\
\hline Visual symptoms & 347 & $51.3 \%$ \\
\hline Urinary symptoms & 400 & $59.2 \%$ \\
\hline Fecal symptoms & 65 & $9.6 \%$ \\
\hline Epilepsy & 21 & $3.1 \%$ \\
\hline
\end{tabular}

Table 14. Patients' distribution according to theirobserved signs.

\begin{tabular}{|c|c|c|}
\hline Signs of MS & No. & $\%$ \\
\hline Facial weakness & 84 & $12.4 \%$ \\
\hline Pyramidal signs & 517 & $76.5 \%$ \\
\hline Cerebellar signs & 344 & $50.9 \%$ \\
\hline Optic nerve signs & 350 & $51.8 \%$ \\
\hline Brainstem signs & 341 & $50.4 \%$ \\
\hline Sensory signs & 335 & $49.6 \%$ \\
\hline Cognitive impairment & 93 & $13.8 \%$ \\
\hline
\end{tabular}

Table 15. Patients' distribution according to the clinical type of their MS.

\begin{tabular}{|c|c|c|}
\hline Clinical type & No. & $\%$ \\
\hline Relapsing remitting multiple sclerosis (RRMS) & 455 & $67.3 \%$ \\
\hline Primary progressive multiple sclerosis (PPMS) & 129 & $19.1 \%$ \\
\hline Secondary progressive multiple sclerosis & 92 & $13.6 \%$ \\
\hline Total & 676 & $100 \%$ \\
\hline
\end{tabular}

Table 16. Patients' distribution according to the type of MS they had and to theirdemographic features.

\begin{tabular}{|c|c|c|c|c|c|c|}
\hline & \multicolumn{2}{|c|}{$\operatorname{PPMS}(n=129)$} & \multicolumn{2}{|c|}{ SPMS $(n=92)$} & \multicolumn{2}{|c|}{ RRMS $(n=455)$} \\
\hline & No. & $\%$ & No. & $\%$ & No. & $\%$ \\
\hline \multicolumn{7}{|c|}{ According to gender } \\
\hline Male $(n=237)$ & 64 & $49.6 \%$ & 36 & $39.1 \%$ & 137 & $30.1 \%$ \\
\hline Female $(n=439)$ & 65 & $50.4 \%$ & 56 & $60.9 \%$ & 318 & $69.9 \%$ \\
\hline $\mathrm{F}: \mathrm{M}$ ratio & $1.01: 1$ & & $1.5: 1$ & & $2.3: 1$ & \\
\hline \multicolumn{7}{|c|}{ According to age at onset } \\
\hline$<20(\mathrm{n}=34)$ & 5 & $3.9 \%$ & 13 & $14.1 \%$ & 16 & $3.5 \%$ \\
\hline
\end{tabular}




\begin{tabular}{|c|c|c|c|c|c|c|}
\hline & \multicolumn{2}{|c|}{ PPMS (n=129) } & \multicolumn{2}{|l|}{ SPMS $(n=92)$} & \multicolumn{2}{|c|}{ RRMS (n= 455) } \\
\hline & No. & $\%$ & No. & $\%$ & No. & $\%$ \\
\hline $40-59(\mathrm{n}=87)$ & 58 & $44.9 \%$ & 15 & $16.3 \%$ & 17 & $3.7 \%$ \\
\hline Mean \pm SD & \multicolumn{2}{|l|}{$39.6 \pm 12.2$} & \multirow{2}{*}{\multicolumn{2}{|c|}{$26.3 \pm 7.9$}} & \multirow{2}{*}{\multicolumn{2}{|c|}{$32.1 \pm 6.7$}} \\
\hline Age at diagnosis & & & & & & \\
\hline$<20(\mathrm{n}=31)$ & 3 & $2.3 \%$ & 13 & $14.1 \%$ & 15 & $3.3 \%$ \\
\hline $20-39(\mathrm{n}=480)$ & 55 & $42.7 \%$ & 65 & $70.7 \%$ & 360 & $79.1 \%$ \\
\hline $40-59(n-165)$ & 71 & $55 \%$ & 14 & $15.2 \%$ & 80 & $17.6 \%$ \\
\hline Mean \pm SD & \multirow{2}{*}{\multicolumn{2}{|c|}{$44.3 \pm 9.6$}} & \multirow{2}{*}{\multicolumn{2}{|c|}{$27.2 \pm 10.2$}} & \multirow{2}{*}{\multicolumn{2}{|c|}{$33.7 \pm 10.3$}} \\
\hline Diagnostic delay & & & & & & \\
\hline$<1$ year $(n=140)$ & 53 & $41.1 \%$ & 17 & $18.5 \%$ & 70 & $15.4 \%$ \\
\hline $1-3(\mathrm{n}=317)$ & 45 & $34.9 \%$ & 51 & $55.4 \%$ & 221 & $48.6 \%$ \\
\hline$\geq 4(\mathrm{n}=219)$ & 31 & $24 \%$ & 24 & $26.1 \%$ & 164 & $36 \%$ \\
\hline Mean \pm SD & \multicolumn{2}{|l|}{$1.3 \pm 1.9$} & \multicolumn{2}{|l|}{$2.6 \pm 2.3$} & \multicolumn{2}{|l|}{$3.5 \pm 3.7$} \\
\hline
\end{tabular}

Table 17. Patients' distribution according to the type ofMS they had and to theirfunctional status expressed in term of EDSS.

\begin{tabular}{|c|c|c|c|c|c|c|}
\hline \multirow{2}{*}{ EDSS } & \multicolumn{2}{|c|}{ PPMS (n=129) } & \multicolumn{2}{|l|}{ SPMS $(n=92)$} & \multicolumn{2}{|c|}{ RRMS (n=455) } \\
\hline & No. & $\%$ & No. & $\%$ & No. & $\%$ \\
\hline $1-3.5$ & 48 & $37.2 \%$ & 0 & $0 \%$ & 253 & $55.6 \%$ \\
\hline $4-6.5$ & 60 & $46.5 \%$ & 67 & $72.8 \%$ & 188 & $41.3 \%$ \\
\hline$\geq 7$ & 21 & $16.3 \%$ & 25 & $27.2 \%$ & 14 & $3.1 \%$ \\
\hline Range & $1-8$ & & $4-9$ & & $1-8$ & \\
\hline Mean \pm SD & $4.6 \pm 2.1$ & & $6.2 \pm 1.01$ & & $3.5 \pm 1.69$ & \\
\hline
\end{tabular}

Table 18. Patients' distribution according to the type ofMS they had and to their treatment at time of diagnosis and at the current time.

\begin{tabular}{|c|c|c|c|c|c|c|}
\hline & \multicolumn{2}{|c|}{ PPMS (n=129) } & \multicolumn{2}{|c|}{ SPMS $(n=92)$} & \multicolumn{2}{|c|}{ RRMS (n= 455) } \\
\hline & No. & $\%$ & No. & $\%$ & No. & $\%$ \\
\hline \multicolumn{7}{|c|}{ According to treatment at diagnosis } \\
\hline Methyl Pednisolone & 129 & $100 \%$ & 92 & $100 \%$ & 445 & $97.8 \%$ \\
\hline Azathioprin & 0 & $0 \%$ & 0 & $0 \%$ & 7 & $1.5 \%$ \\
\hline Prednisolone & 0 & $0 \%$ & 0 & $0 \%$ & 3 & $0.7 \%$ \\
\hline \multicolumn{7}{|c|}{ According to current treatment } \\
\hline Methyl Pednisolone & 121 & $93.8 \%$ & 63 & $68.5 \%$ & 46 & $10.1 \%$ \\
\hline Rebif $₫$ & 8 & $6.2 \%$ & 29 & $31.5 \%$ & 409 & $89.9 \%$ \\
\hline
\end{tabular}

Table 19. Patients' distribution according to their EDSS and gender.

\begin{tabular}{lllll}
\hline \multirow{2}{*}{ EDSS } & Male $(\mathbf{n}=\mathbf{2 3 7})$ & & Female $(\mathbf{n}=\mathbf{4 3 9})$ & \\
\cline { 2 - 5 } & No. & $\mathbf{\%}$ & No. & \% \\
\hline $1-3.5$ & 77 & $32.5 \%$ & 224 & $51 \%$ \\
$4-6.5$ & 128 & $54 \%$ & 186 & $42.4 \%$ \\
$\geq 7$ & 32 & $13.5 \%$ & 29 & $6.6 \%$ \\
Range & $1-9$ & & $1-7.5$ & \\
Mean \pm SD & $3.98 \pm 2.02$ & & $3.4 \pm 1.83$ & \\
\hline
\end{tabular}

Table 20. Patients' distribution according to their EDSS and disease duration.

\begin{tabular}{|c|c|c|c|c|c|c|c|}
\hline \multirow{3}{*}{ Disease duration (year) } & \multicolumn{6}{|c|}{ EDSS } & \multirow{3}{*}{ Total Number } \\
\hline & \multicolumn{2}{|c|}{$0-3.5$} & \multicolumn{2}{|c|}{$4-6.5$} & \multicolumn{2}{|l|}{$\geq 7$} & \\
\hline & No. & $\%$ & No. & $\%$ & No. & $\%$ & \\
\hline $0-4.9$ & 108 & $72 \%$ & 40 & $26.7 \%$ & 2 & $1.3 \%$ & 150 \\
\hline $5-9.9$ & 112 & $39.7 \%$ & 160 & $56.7 \%$ & 10 & $3.6 \%$ & 282 \\
\hline $10-14.9$ & 57 & $39.9 \%$ & 73 & $51 \%$ & 13 & $9.1 \%$ & 143 \\
\hline $15-19.9$ & 20 & $25.6 \%$ & 47 & $60.3 \%$ & 11 & $14.1 \%$ & 78 \\
\hline$\geq 20$ & 4 & $17.4 \%$ & 14 & $60.9 \%$ & 5 & $21.7 \%$ & 23 \\
\hline
\end{tabular}

\section{Discussion}

The past fifteen years has witnessed an explosion of interest in multiple sclerosis sparked by a combination of advances in unraveling the basic science of the disease and the introduction of the first medications that alter the natural history of this still-mysterious disorder [24]. Focused efforts over the past two decades have resulted in development of powerful longitudinal databases that allow assessment of the contribution of individual genetic and environmental influences on MS susceptibility and disease course. These efforts has allowed refinement of risk assessment for individuals deemed at risk for MS, facilitated the development of preventive therapies, and identified factors that influence treatment decisions such as prediction of response to a specific therapy [25]. MS can be considered as one of the most important health problems that consume 
good portion of the health cost. About 300,000 to 350,000 people are estimated to have MS in the United States, incurring a cost of about $\$ 10$ billion per year at 1994 [26]. One can imagine the economic burden of MS as up to 2 million people are affected worldwide, an all of the economic effect of this disease in term of cost of direct health care, in addition to lost productivity [27]. Despite the introduction of disease modifying treatments with modest effect on overall disease outcome, current costs are much higher [28-29].

The prevalence of MS across most of Asia is low [30]. Low prevalence rates were reported in Taiwan $(0.8$ per 100,000) [31], China (0.77-0.88 per 100,000) [32-33], India $(0.22-0.6$ per 100,000$)$ [34], Korea $(1.8-2.0$ per 100,000$)$ [3536], Malaysia (2.0 per100,000) [37] and Thailand (2.0 per 100,000) [38]. Medium prevalence rates have been reported in Arabic populations, particularly in Mediterranean populations (Jordan, 20 per 100,000 and Palestine 42 per 100,000) [39] in which prevalence is higher than inGulf populations (Kuwait, 9.5 per 100,000, and Saudi Arabia, 8.0 per 100,000) [40, 41]. In Iraq, no specific idea about the frequency of MS among different Iraqi populations could have been obtained before establishing the MS clinic in 2000 at Baghdad Teaching Hospital. A report on MS in Iraq, published at 1958 , described only 13 patients with MS, seen between 1944 and 1954 [42]. During our study period, 676 files had been evaluated, furthermore, additional 245 files had been excluded from the evaluation because they were did not continued their visiting to the Clinic and did not complete their investigations which are required for definite diagnosis of MS. This major increase in the number of cases seen over 60 years must rise many questions to be asked in order to reach the point of well understanding about the nature and the size of MS as a health problem in our country. This study revealed that there was a progressive rise in the number of diagnosed cases over more than 25 years period, it had been found that no cases had been diagnosed before 1985, while 518 out of 676 cases $(76.6 \%$ of the evaluated cases) had been diagnosed after the establishment of the MS clinic i.e. 2000 and after (see table-6). This considerably larger number of patients diagnosed with MS during the current decade can be explained by the following factors:

1- Better case ascertainment and the higher number of welltrained neurologist available to supply their diagnostic and medical care services. Benedikz et al showed in their study that over 100 year period, the incidence of MS in Iceland raised from 0.25 per 100,000 population at $1901-1905$ to $3.71-5.28$ cases per 100,000 population during the 1990s. This progressive increase in the incidence had been associated with similar increase in number of neurologist in Iceland that there was no neurologist in Iceland at 1909 while 15 neurologists provided their medical care to the population of Iceland in the 1990s [43].

2- Recent improvements in MS therapy, particularly the introduction of the interferons in the $1990 \mathrm{~s}$, have heightened public awareness of the disease and may have brought patients to medical attention earlier [44].

3- The availability of modern investigatory techniques such as MRI and inclusion of these investigations as a diagnostic criteria for MS. Barnett et al found that the introduction of MRI finding into the diagnosis of MS was consistent with the finding that a greater proportion of patients with shorter disease duration $(<10$ years) were included in the recent years of their study [45].

4- It is important to consider that prevalence studies performed at different time points are subject to certain hazards. The diagnostic criteria for MS continue to evolve. In most studies, the diagnosis has been ascertained by clinical criteria, generally the Schumacher or Poser criteria. The application of the incompletely validated McDonald criteria will increase the prevalence because MRI lesion activity, sufficient for the MRI-based diagnostic criteria, commonly precedes clinical activity. Increasing awareness of MS, earlier recognition of cases, and prolonged survival pose additional challenges for the epidemiologist [46].

5- This increase in the number of MS cases that had been diagnosed during this decade might point also toward an undetermined environmental or socioeconomic factors.

A female preponderance of nearly two women to every man with MS has long been recognized [47, 48], in agreement with the data from other autoimmune disorders, such as systemic lupus erythematosus [49] and rheumatoid arthritis [50]. Our study indicated a female to male ratio of about $1.85: 1$, which is quite similar to the ratio of 2 females to 1 male described above. The role of gender in transmission is yet to be clearly defined. In a paper published at 2002, it had been hypothesized that microchimerism increases susceptibility to MS and may have a direct relationship to the gender bias in MS [51]. In addition, Riepert B. in his short review about MS and the difference in gender distribution proposed that this difference is probably due to sex hormones and he had concluded from animal studies that testosterone has some protective effect against the disease [52]. However, gender distribution of cases with MS seems to be affected by the age of onset, varied geographically, and might be reversed in certain clinical types of MS.

It had been considered that the female to male ratio seems to increase with onset prepuberty $[53,54]$. In a study done at Japan and enrolled patients with childhood onset MS, it had been revealed that 19 out of the 27 cases included in the study was female carrying a female to male ratio of about 2.4:1 [55]. However, the results of our study showed no higher female preponderance specific to prepuberty age group, it showed that the female to male ratio was 1.6:1 among those who were younger than 20 year-old which was not higher or even it was less than the ratio observed in the other age groups. This finding could be related to the geographic variation that could affect the gender distribution of MS patients. On reviewing the female to male ratio of different countries enlisted one can found the prominent 
difference in this ratio between different areas of the world, in addition, the ratio of 1.85:1 that had been estimated from the data of our study appeared to be quite similar to the ratios estimated in the neighboring countries like Jordan (1.9:1) [56], Saudi Arabia (1.34:1) [57], Kuwait (1.7:1) [58], and Iran (1.52:1) [59].

Table 21. Female to male ratio estimated in different countries.

\begin{tabular}{llll}
\hline Country & F:M & Country & F:M \\
\hline Iraq (current study) & $1.85: 1$ & England [96] & $2.6: 1$ \\
Jordan [80] & $1.9: 1$ & Malaysia [78] & $5: 1$ \\
Saudi Arabia [81] & $1.34: 1$ & Thailand [79] & $4: 1$ \\
Kuwait [82] & $1.7: 1$ & Taiwan [72] & $3.2: 1$ \\
Iran [95] & $1.52: 1$ & Hong Kong [73] & $2.9: 1$ \\
& & Korea [76] & $0.47: 1$ \\
& & Japan [97,98] & $1.5-6: 1$ \\
\hline
\end{tabular}

The other important feature in the gender distribution of multiple sclerosis is that female preponderance could be less prominent or even reaching the degree of equalfrequency between male and female populations, as in cases of primary progressive MS where male might be more equally affected [60], or male exceeds females, at least for patients age 25-35 years as it was shown by the results of Cottrel et al study [61]. Our study showed that the males were nearly equally affected in comparison with females, carrying a female to male ratio of about 1.01:1. Recent study confirmed this finding of lack of female preponderance in primary progressive MS, independent of age of onset [62].

In regard to the possible effect of gender on the disease severity and degree of functional disabilities termed in form of EDSS score, our study showed that not only the mean EDSS score is lower among females (3.4 versus 3.98) but also the number of female MS patients with EDSS score of less than 4 was much higher than what had been observed among male patients $(51 \%$ of females versus $32.5 \%$ of males). It is well known that MS appears to follow a more benign course in women than in men [63], and female sex has been considered as one of the demographic features of benign MS [64].

In regard to the frequency of positive family history in MS patients, it had estimated that $6.7 \%$ of included sample (45 patients) had positive family history of MS. This frequency is supported by what had been concluded by Dyment et al who found that $3-5 \%$ is the age adjusted recurrence risk of MS in patients with positive family history in their first degree relatives [65].

Relapsing remitting MS was the most frequent clinical type of MS observed in our sample, comprising $67.3 \%$ of the sample, followed by the primary progressive MS $(19.1 \%$ of the sample) and secondary progressive MS (13.6\% of the sample). This percentages were little bit lower than what had been estimated by other study in regard to the relapsing remitting type $(85 \%)$ and little bit higher in regard to the primary progressive pattern (15\%) [66-68]. This higher frequency of primary progressive MS, observed in our study in comparison with other studies, might be due to variations in definitions used and the lack of uniformity in criteria applied. Therefore, it is not easy to accurately ascertain the proportion of MS patients who follow a primary progressive course [69]. This is reflected in estimates from both clinicbased and population-based surveys, where figures vary between $9-26 \%[70,71]$ and $10-37.4 \%$ [72, 73], respectively. In one detailed study of 349 patients, most of whom had been admitted to hospital at least once and were seen twice yearly, $18 \%$ were considered to have progressive disease from onset [74], a frequency that is quite similar to the frequency of primary progressive MS observed in our sample.

It is potentially important to mention that our study showed that cases with primary progressive MS tended to be older than other cases (mean age was 39.6 years for PPMS, 26.3 years for SPMS, and 32.1 years for RRMS). This finding is consistent with the results of many studies which had reported the mean age at onset, in cases with PPMS, as 43 by Shepherd [75], 37.3 by Confavreux et al [76], 37.5 by Minderhoud et al [77], 38.5 by Weinshenker et al [78], 41.2 by Andersson et al [79] and 39.5 by McDonnel and Hawkins [80]. Furthermore, our study indicated that 58 out of 87 patients $(66.7 \%)$, whose were 40 years or older, had progressive course from the onset of their MS. This is supported by the results of Leibowitz et al [81] and Cazullo et al [82] who found that $57 \%$ and $49 \%$, respectively, of those with onset after age 40 had a primary progressive course. Interestingly, the Ontario cohort has also demonstrated that with each passing decade, there is a steadily increasing proportion of patients with progressive disease from onset [83].

In addition, it had been observed from analyzing the data obtained from our study, that the diagnostic delay was the shortest in patients with PPMS (mean diagnostic delay was 1.3 years) with $41.1 \%$ of those with PPMS diagnosed within the first year from the onset of their symptoms. This finding of earlier diagnosis can be related to the agreement of many other studies that the time required to reach a given level of disability is shorter in patients with primary progressive form [84, 85].

In this study, it had been observed that the mean EDSS at the time of registration in the MS clinic was significantly lower in the RRMS group (3.5) compared to 6.2 in SPMS and 4.6 in PPMS patients. As mentioned above, RRMS had been considered as one of the good prognostic feature in the natural history of MS. In a total population based 50 year prospective study done at Iceland by Benedikz et al [86], it had been shown that after 15 years, only $20 \%$ have progressed beyond and EDSS of 3.5 , thus $80 \%$ have remained in the benign group. While by 15 years, $80 \%$ of those with primary progressive course have reached EDSS of 4 or more, and of those half become severe i.e. $\geq 7$. After 30 years more than $60 \%$ of those with primary progressive course have become severe and the rest have an EDSS of 4 or more [84]. The current study showed also that $82.6 \%$ of those with MS for 20 years or more had an EDSS of 4 or more.

In this study sample, all of those with secondary progressive course had an EDSS of 4 or more with a mean EDSS of about 6.2, which was the highest in comparison 
with the means of other clinical types. This finding can be supported by that in the Lyon Natural History MS cohort, it had been concluded that the time course of disability accumulation during the progressive phase of the disease was more rapid in secondary progressive MS than in primary progressive MS [87, 88]. This finding is in agreement with those from other series $[89,90]$.

On reviewing the maps showing the distribution of Iraqi MS patients according to their place of birth and place of current residence, no clear geographic gradient can be concluded. Although the number of cases born in Naynawa was 52 and those born in Muthana in the south of Iraq was only 6 , but the geographic distribution of the patients seemed to be concentrated in a geographic clusters. These clusters included, from north to south, Naynawa (52 patients), Salahuddin (37 patients), Diyala (30 patients), Baghdad (320 patients), and Basra (25 patients). These clusters sited in areas where medical facilities were available more and where well trained physicians and/or neurologist were available in larger number. What can support this finding, was that just adjacent to these clusters, there were areas having only few patients in their territories. One can notice that the number of Iraqi MS patients born in Dohuk governorate at the far north of Iraq, which is adjacent to the cluster of Naynawa, was just 8 patients. Similarly, the number of patients born in Muthana Governorate in the far south of Iraq, which is adjacent to the cluster of Basra, was just 6 patients. One of the possible explanation is that the differences in the performance and availability of medical services between adjacent governorates and the difference in the knowledge and index of suspicion about MS. This can be supported by the finding that in Baghdad, where the medical services and performance supposed to be the best in Iraq, the number of cases born or lived in Baghdad was 10 times or more higher in comparison to any other governorate.

The interesting finding about the nature of MS in Iraqi patients was the predominance of motor symptoms and signs at the time of registration in the MS clinic. $95.7 \%$ of the patients (647 patients) had motor symptoms at registration or at anytime prior to it, followed in term of frequency by the sensory symptoms (65.2\% of the sample). Rot and Mesec showed in their retrospective study, which had been published recently, that motor and sensory symptoms were more equally distributed in relapsing remitting MS, while motor symptoms predominated in primary progressive MS and were found in over $90 \%$ of patients [91]. However, in a study done at Iran by Ale-Yasin et al, it had been shown that only $13.7 \%$ of their sample had motor symptoms at presentation [95]. This higher frequency of motor dysfunction detected in our sample in comparison with the Iranian sample, might be related to the higher frequency of primary progressive MS observed in our sample. Furthermore, this big difference in frequency of motor disabilities can be caused by the differences in the method of case ascertainment between our study and the Iranian study. Our method was much closer to the method used by Rot and Mesec who analyze retrospectively MS patients attending the biggest medical center in Slovenia. While, the method of case ascertainment in the Iranian study was by announcement in 2 national newspapers inviting MS patients to participate in the study, this could cause loss of many cases with motor dysfunction, who could not walk and present themselves to the research workers in the Iranian study. It is vital to mention that the importance of discovering motor signs in patients with MS comes from that involvement of motor functions is considered as one of the unfavorable prognostic indicators in multiple sclerosis [92].

\section{Conclusions and Recommendations}

During the last 2 decades, MS was increasingly encountered in Iraq, particularly during the last 5 years after the establishment of MS clinic in Baghdad.

Regardless of the clinical type or age, females predominate the frequency of MS in Iraq in a ratio that is not quite different from what was observed in other epidemiological studies.

The age of onset of most of the MS cases in Iraq laid in the $3^{\text {rd }}$ and the $4^{\text {th }}$ decades of life.

MS cases in Iraq distributed in a three main clusters pattem rather than North-South gradient.

Relapsing remitting MS was the most frequent form encountered in Iraq.

Primary progressive MS showed a more even gender distribution and older age at onset with the shortest diagnostic delay.

Secondary progressive MS was the least common clinical type, with younger age at onset, and most severe disability.

Most of MS patients had negative family history of the disease.

Motor symptoms and signs were the most frequently encountered clinical features followed by the sensory symptoms and signs.

Most of the cases had either mild or moderate disease depending on their EDSS scoring.

Relapsing remitting form of MS and being female were associated with the mildest severity

With increasing duration of the disease, functional disabilities showed a progressive increase in frequency and more cases pass toward the moderate or the severe forms.

It is recommended to establish an electronic medical filing system, that can be used as a fundamental base for an informative database which can help the medical staff and research workers to know more about the nature of MS as one of the evolving health problems in Iraq and allowing proper planning for better medical services provision to such unlucky patients with such a disabling disease.

It is recommended also to arrange and make prospective studies that involve good bulk of MS patients in Iraq and focus on any possible difference in response to the available treatment and its effect on the overall natural history of this disease in patients receiving such a costy medication. 


\section{References}

[1] Dawson DM. Multiple sclerosis and other demyelinating diseases. In: Samuels MA (ed). Manual of Neurologic Therapeutics. Philadelphia: Lippincott Williams \& Wilkins. 2004:179-90.

[2] Gatley K. The historical maze of multiple sclerosis. Lancet Neurol 2005; 4:

[3] Aminoff MJ. Nervous system. In: Tierney LM, McPhee SJ, Papadakis MA, eds. Current Medical Diagnosis and Treatment. Lange Medical Books/McGraw-Hill: New York. 2005; 983.

[4] Pugliatti M, Sotgiu S, Rosati G. The worldwide prevelance of multiple sclerosis. Clinical Neurology and Neurosurgery 2002; 104: 182-91.

[5] Rosati G. Descriptive epidemiology of multiple sclerosis in Europe in the 1980s: a critical overview. Ann Neurol 1994; 36 (Suppl 2):S164 - 74.

[6] Sadovnick A, Ebers G. Epidemiology of multiple sclerosis: a critical overview. Can J Neurol Sci 1993; 20:17-29.

[7] Noseworthy J, Lucchinetti C, Rodriguez M, Weinshenker B. Multiple sclerosis. N Engl J Med 2000; 343: 938-52.

[8] Marrie RA. Environmental risk factors in multiple sclerosis etiology. Lancet Neurol 2004; 3: 709-18.

[9] Pugliatti M, Sotgiu S, Rosati G. The worldwide prevalence of multiple sclerosis. Clin Neurol Neurosurg 2002; 104: 182-91.

[10] Kurtzke JF. A reassessment of the distribution of multiple sclerosis. Part one. Acta Neurol Scand 1975; 51: 110-36.

[11] AI-Araji A, Mohammed Al. Multiple sclerosis in Iraq: does it have the same features encountered in Western countries. J Neurol Sciences 2005; 234: 67-71.

[12] Sumelahti M-L, Tienari PJ, Hakama M, Wikstrom J. Multiple sclerosis in Finland:incidence trends and differences in relapsing remitting and primary progressive disease courses. $\mathrm{J}$ Neurol Neurosurg Psychiatry 2003; 74: 25-28.

[13] McGuigan C, McCarthy A, Quigley C, Bannan L, Hawkins SA, Hutchinson M. Latitudinal variation in the prevalence of multiple sclerosis in Ireland, an effect of genetic diversity. J Neurol Neurosurg Psychiatry 2003; 75: 572-76.

[14] Amerindians, Samis, Hutterites, Maoris. Microsoft Encarta Premium DVD 2006: an electronic based encyclopedia, accessed April 2006.

[15] Page WF, Kurtzke JF, Murphy FM, Norman JE. Epidemiology of multiple sclerosis in U.S. Veterans: V. Ancestry and the risk of multiple sclerosis. Ann Neurol 1993; 33: 632-39.

[16] Dyment DA, Sadovenick AD, Ebers GC. Genetics of multiple sclerosis. Hum Mol Genet 1997; 6: 1693-8.

[17] Weiner I-IL. A 21 point unifying hypothesis on the etiology and treatment of multiple sclerosis. Can J Neurol Sci 1998; 25: 93-101.

[18] Cooper GS, Stroehla BC. The epidemiology of autoimmune diseases. Autoimmun Rev 2003; 2: 119-25.
[19] Confavreux C, Hutchinson M, Hours MM, CortinovisTourniaire P, Moreau T, for the Pregnancy in Multiple Sclerosis Group. Rate of pregnancy-related relapse in multiple sclerosis. N Engl J Med 1998; 339: 285-91.

[20] Broadley SA, Deans J, Sawcer SJ, Clayton D, Compston DAS. Autoimmune disease in first-degree relatives of patients with multiple sclerosis. A UK survey. Brain 2000; 123:110211 .

[21] Dyment DA, Ebers GC, Sadovnick AD. Genetics of multiple sclerosis. Lancet 2004; 3:104-10.

[22] Keegan BM, Nosewoflhy JH. Multiple sclerosis. Ann Rev Med 2002; 53: 285-302.

[23] Dyment DA, Ebers GC, Sadovnick AD. Genetics of multiple sclerosis. Lancet Neurol 2004; 3: 104-10.

[24] Peterson JW, Bo L, Mork S, Chang A, Trapp BD. Transected neurites, apoptotic neurons, and reduced inflammation in cortical multiple sclerosis lesions. Ann Neurol 2001; 50:389400 .

[25] Ferguson B, Matyszak MK, Esiri MM, Perry VH. Axonal damage in acute multiple sclerosis lesions. Brain 1997; 120: 393-99.

[26] Trapp BD, Peterson J, Ransohof RM, Rudick R, Mork S, Bo L. Axonal transection in the lesions of multiple sclerosis. $\mathrm{N}$ Engl J Med 1998; 338: 278-85.

[27] Trapp BD, Ransohoff RM, Fisher E, Rudick RA. Neurodegeneration in multiple sclerosis: relationship to neurological disability. Prog Clin Neurosci 1999; 5: 48-57.

[28] Lucchinetti C, Bruck W, Parisi J, Scheithauer B, Rodriguez M, Lassman H. Heterogeneity of multiple sclerosis lesions: implications for the pathogenesis of demyelination. Ann Neurol 2000; 47: 707-17.

[29] Rice GPA. Virology. In: Paty DW, Ebers GC. Multiple Sclerosis (Contemporary Neurology, No. 50). Oxford University Press, 1999: 382-402.

[30] Eichhorst H. Veber infantile und hereditare multiple sklerosis. Arch Pathol Anat Physiol Klin Med 1896; 146: 173-92.

[31] Mackay RP. The familial occurrence of multiple sclerosis and its implications. Res Publ Assoc Res Nerv Ment Dis 1950; 28: 149-77.

[32] Jersild C, Svejgaard A, Fog T. I-ILA antigens and multiple sclerosis. Lancet 1972; 2:1240-41.

[33] Naito S, Namerow N, Mickey M, Teraski P. Multiple Sclerosis: association with HL-A3. Tissue Antigens 1972; 2: 1-4.

[34] Ebers GC, Sadovnick AD, Risch NJ, for the Canadian Collaborative Study Group. A genetic basis for familial aggregation in multiple sclerosis. Nature 1995; 377: 150-51.

[35] Ebers GC, Sadovnick AD. The Geographic Distribution of Multiple Sclerosis: a review. Neuroepidemiology 1993; 12:1-5.

[36] Dyment DA, Willer CJ, Scott B, et al. Genetic susceptibility to MS: a second stage analysis in Canadian MS families. Neurogenetics 2001; 3: 145-51.

[37] Sadovnick AD, Armstrong H, Rice GPA, et al. A populationbased study of multiple sclerosis in twins: update. Ann Neurol 1993; 33: 281-85. 
[38] Sadovnick AD, Ebers GC, Dyment DA, Risch NJ. Evidence for genetic basis for multiple sclerosis. The Canadian Collaborative Study Group. Lancet 1996; 347: 1728-30.

[39] Cook SD, Dowling PC. Multiple sclerosis and viruses: an overview. Neurology 1980; 30: 80-91.

[40] Haire M. Significance of virus antibodies in multiple sclerosis. Br Med Bull 1977; 33:40-44.

[41] Casetta I, Granieri E, Malagu S, et al. Environmental risk factors and multiple sclerosis:a communitybased, case-control study in the province of Ferrara, Italy. Neuroepidemiology 1994; 13: 120-28.

[42] Souberbielle BE, Martin-Mondiere C, O'Brien ME, Carydakis C, Cearo P, Degos JD. A case-control epidemiological study of MS in the Paris area with particular reference to past disease history and profession. Acta Neurol Scand 1990; 82: 303-10.

[43] Zorzon M, Zivadinov R, Nasuelli D, et al. Risk factors of multiple sclerosis: a casecontrol study. Neurol Sci 2003; 24:242-47.

[44] Stenager E, Bronnum-Hansen H, Koch-Henriksen N. Risk of multiple sclerosis in nurse anesthetists. Mult Scler 2003; 9: 427-28.

[45] Flodin U, Landtblom A-M, Axelson O. Multiple sclerosis in nurse anesthetists. Occup Environ Med 2003; 60: 66-68.

[46] Koch-Henriksen N. An epidemiological study of multiple sclerosis. Familial aggregation, social determinants, and exogenic factors. Acta Neurol Scand 1989; 124: 1-123.

[47] Riise T, Moen BE, Kyvik KR. Organic solvents and the risk of multiple sclerosis. Epidemiology 2002; 13: 718-20.

[48] Mortensen JT, Bronnum-Hansen H, Rasmussen K. Multiple sclerosis and organic solvents. Epidemiology 1998; 9: 168-71.

[49] Flodin U, Soderfeldt B, Noorlind-Brage H, Fredriksson M, Axelson O. Multiple sclerosis, solvents, and pets. Arch Neurol 1988; 45: 620-23.

[50] Amaducci L, Arfaioli C, Inzitari D, Marchi M. Multiple sclerosis among shoe and leather workers: an epidemiological survey in Florence. Acta Neurol Scand 1982; 65:94-103.

[51] Landtblom A-M, Flodin U, Karlsson M, Palhagen S, Axelson O, Soderfeldt B. Multiple sclerosis and exposure to solvents, ionizing radiation and animals. Scand J Work Environ Health 1993; 19: 399-404.

[52] Gronning M, Albrektsen G, Kvale G, Moen BE, Aarli JA, Nyland H. Organic solvents and multiple sclerosis: a casecontrol study. Acta Neurol Scand 1993; 88: 247-50.

[53] Nelson NA, Robins TG, White RF, Garrison RI). A casecontrol study of chronic neuropsychiatric disease and organic solvent exposure in automobile assembly plant workers. Occup Environ Med 1994; 51: 302-07.

[54] Juntunen J, Kinnunen E, Antti-Poika M, Koskenvuo M. Multiple sclerosis and occupational exposure to chemicals: a co-twin control study of a nationwide series of twins. Br J Ind Med 1989; 46: 417-19.

[55] Hayes CE. Vitamin D: A natural inhibitor of multiple sclerosis. Proc Nutr Soc 2000; 59:531-35.

[56] Fox RJ, Bethoux F, Goldman MD, Cohen JA. Multiple sclerosis: advances in understanding, diagnosing, and treating the underlying disease. Cleveland Clinic J Med 2006; 73: 91102 .

[57] Beck RW, Trobe JD, Moke PS, et al. High- and low-risk profiles for the development of multiple sclerosis within 10 years after optic neuritis: experience of the optic neuritis treatment trial. Arch Ophthalmol 2003; 121: 944-49.

[58] Bobholz JA, Rao SM. Cognitive dysfunction in multiple sclerosis: a review of recent development. Curr Open Neurol 2003; 16: 283-8.

[59] Goldmen MD, Cohen JA, Fox RAJ, Bethoux FA. Multiple sclerosis: treating symptoms and other general medical issues. Cleveland Clinic J Med 2006; 73: 177-86.

[60] Multiple sclerosis and allied demyelinative diseases. In: Ropper AH, Brown RH, eds. Adams and Victor's Principles of Neurology. New York: McGraw-Hill. 2005: 771-796.

[61] Lucchinetti CF, Mandler RN, McGavern D, et al. A role for humoral mechanisms in the pathogenesis of Devic's neuromyelitis optica. Brain 2002; 125: 1450-61.

[62] Lublin FD, Reingold SC. Defining the clinical course of multiple sclerosis: results of an international survey. Neurology 1996; 46: 907-11.

[63] Poser CM, Paw DW, Scheinberg L, McDonald WI, Davis FA, Ebers GC, Johnson KP, Sibley WA, Silberberg DH \& Tourtellotte WW. New diagnostic criteria for multiple sclerosis: guidelines for research protocols. Ann Neurol 1983; 13:227-31.

[64] Miller AE. Editor's preface. Continuum, life long learning in neurology: Multiple Sclerosis. 2004; December: 9.

[65] Orhun K, Dean W. Epidemiology and natural history of multiple sclerosis: new insights. Curr Opinion Neurol 2006; 19: $248-54$.

[66] Whetten-Goldstein K, Sloan FA, Goldstein LB, Kulas ED. A comprehensive assessment of the cost of multiple sclerosis in the United States. Mult Scler 1998; 4:419-425.

[67] Richards RG, Simpson FC, Beard SM, Tappenden P. A review of the natural history and epidemiology of multiple sclerosis: implications for resource allocation and health economic models. Health Technology Assessment 2002; vol.6: No. 10, pp 1-73.

[68] Group TIMSS. Interferon beta-lb is effective in relapsingremitting multiple sclerosis. I. Clinical results of a multicenter, randomized, double-blind, placebo-controlled trial. Neurology $1993 ; 43: 655-61$

[69] Johnson KP, Brooks BR, Cohen JA, et al. Copolymer 1 reduces relapse rate and improves disability in relapsingremitting multiple sclerosis: results of a phase Ill multicenter, double-blind placebo-controlled trial. The Copolymer 1 Multiple Sclerosis Study Group. Neurology 1995; 45:126876.

[70] Hartung HP, Gonsette R, Konig N, et al. Mitoxantrone in progressive multiple sclerosis:a placebo-controlled, doubleblind, randomised, multicentre trial. Lancet 2002; 360:201825 .

[71] Kira J. Multiple sclerosis in the Japanese population. Lancet Neurol 2003; 2: 117-27.

[72] Hung TP, Landsborough D, Hsi MS. Multiple sclerosis amongst Chinese in Taiwan. J Neurol Sci 1976; 27: 459-84. 
[73] Yu YL, woo E, Hawkins BR, Cho HC, Huang CY. Multiple sclerosis amongst Chinese in Hong Kong. Brain 1989; 112: 1445-67.

[74] Lau KK, Wong LKS, Li LSW, Chan YW, Li HL, Wong V. Epidemiological study of multiple sclerosis in Hong Kong Chinese: questionnaire survey. Hong Kong Med J 2002; 8: 77 80 .

[75] Singhal BS. Clinical profile and HLA-studies in Indian multiple sclerosis patients from the Bombay region. In: Kuroiwa Y, Kurland LT, eds. Multiple sclerosis East and West. Fukuoka: Kyushu University Press, 1982: 123-34.

[76] Kurtzke JF, Park CS, Oh SJ. Multiple sclerosis in Korea: clinical features and prevalence. J Neurol Sci 1968; 6: 46381 .

[77] Kim S W, Kim SK. Multiple sclerosis in Busan, Korea: clinical features and prevalence. In: Kuroiwa Y, Kurland LT, eds. Multiple sclerosis East and West. Fukuoka: KyushuUniversity Press, 1982: 57-70.

[78] Tan CT. Multiple sclerosis in Malaysia. Arch Neurol 1988; 45: 624-27.

[79] Vejjajiva A. Some clinical aspects of multiple sclerosis in Thai patients. In: Kuroiwa Y, Kurland LT, eds. Multiple sclerosis East and West. Fukuoka: Kyushu University Press, 1982: 11721.

[80] Al-Din ASN, El-Khateeb M, Kurdi A, et al. Multiple sclerosis in Arabs in Jordan. J Neurol Sci 1995; 131: 144-49.

[81] Yaqub BA, Daif AK. Multiple sclerosis in Saudi Arabia. Neurology 1988; 38: 621-23.

[82] Al-Din ASN, Khogali M, Poser CM, et al. Epidemiology of multiple sclerosis in Arabs in Kuwait: a comparative study between Kuwaitis and Palestinians. J Neurol Sci 1990; 100: $137-41$.
[83] Shabby JA. Multiple sclerosis in Iraq. Wien Z Nervenheilkd 1958; 15: 267-83.

[84] Benedikz J, Steansson M, Guomundsson J, et al. The natural history of untreated multiple sclerosis in Iceland: a total population-based 50 year prospective study. Clinic Neurol Neurosurg 2002; 104: 208-10.

[85] Barnett MH, Williams DB, Day S, Macaskill P, McLeod JG. Progressive increase in incidence and prevalence of multiple sclerosis in Newcastle, Australia: a 35-year study. J Neurol Sci 2003; 213: 1-6.

[86] Rice GPA. The genetic epidemiology of multiple sclerosis. Continuum, life long learning in Neurology: multiple sclerosis 2004; December: 28-37.

[87] O'Connor P on behalf of the Canadian Multiple Sclerosis Working Group. Key issues in the diagnosis and treatment of multiple sclerosis. Neurology 2002; 59 (suppl 3): S 1-33.

[88] Voulgari PV, Katsimbri P, Alamanos Y, Drosos AA. Gender and age differences in systemic lupus erythematosus: a study of 489 Greek patients with a review of the literature. Lupus 2002; 11: 722-29.

[89] Symmons DI). Epidemiology of rheumatoid arthritis: determinants of onset, persistence and outcome. Best Pract Res Clin Rheumatol 2002; 16: 707-22.

[90] Willer CJ, Sadovnick AD, Ebers GC. Microchimerism in autoimmunity and transplantation: potential relevance to multiple sclerosis. J Neuroimmunol 2002; 126: 126-33.

[91] Reipert B. Multiple sclerosis: a short review of the disease and its differences between men and women. Journal of Men's Health \& Gender 2004; 1: 334-40.

[92] Duquette P, Murray TJ, Pleines J, et al. Multiple Sclerosis in childhood: clinical profile in 125 patients. J Pediat 1987; 111: 359-63. 